\title{
Eduard Cuelenaere*, Stijn Joye and Gertjan Willems Local flavors and regional markers: The Low Countries and their commercially driven and proximity-focused film remake practice
}

https://doi.org/10.1515/commun-2019-2057

\begin{abstract}
The practice of Dutch-Flemish film remaking that came into existence in the new millennium quickly appeared to be of great importance in the film industries of Flanders and The Netherlands - and consequently of Europe. Inspired by methods used in television (format) studies, this article conducts a systematic comparative film analysis of nine Dutch-Flemish remakes together with their nine source films. Considering the remake as a prism that aids in dissecting different formal, transtextual, and cultural codes, and subsequently embedding the practice in its specific socio-cultural and industrial context, we found several similarities and differences between the Dutch and Flemish film versions and showed how these can be made sense of. More generally, we distilled two encompassing principles that administer the remake practice: even though a great deal of the remake process can be explained through the concept of localization - or, more precisely, through the concepts of 'manufacturing proximity' and 'banal aboutness' - we found that it should certainly not be limited to these processes - as both (trans)textual, such as the mechanism of 'filling in the gaps', and contextual elements were found.
\end{abstract}

Keywords: transnational film remakes, local-language remakes, Low Countries, comparative film analysis, European cinema

\footnotetext{
*Corresponding author: Eduard Cuelenaere, Centre for Cinema and Media Studies, Ghent University/University of Antwerp, Department of Communication Sciences, Ghent, Belgium, E-Mail: Eduard.Cuelenaere@UGent.be.

Stijn Joye, Centre for Cinema and Media Studies, Ghent University, Department of Communication Sciences, Ghent, Belgium, E-Mail: Stijn.Joye@UGent.be.

Gertjan Willems, Visual Poetics/ViDi/CIMS, Departments of Literature and of Communication Sciences, University of Antwerp/Ghent University, Ghent, Belgium, E-Mail: Gertjan.Willems@uantwerpen.be.
} 


\section{Introduction}

In 2000, Flemish ${ }^{1}$ film director Jan Verheyen released Team Spirit, a mainstream (romantic) comedy about a group of friends who play football in a regional team. Although the popularity of Flemish films had strongly declined at the time, the film did very well at the domestic box office. Combined with the highly successful spin-off television series Team Spirit (2003-2006) and the popular sequel Team Spirit II (2003), Flanders saw the birth of a genuine transmedial Team Spirit-franchise. Interestingly enough, the apparent 'original' Team Spirit film was a film remake of an equally popular Dutch film released in 1997, called All Stars, directed by Jean van de Velde. Almost two decades later, it seems that this series of interrelated media products set a precedent for a remake practice that became structurally embedded in the Flemish film industry: No less than seven Dutch films were remade in Flanders in a time span of only 18 years. Moreover, this Dutch-Flemish remake phenomenon is not unidirectional. The first Dutch remake of a Flemish film was released in 2010: Loft, a remake of Belgium's biggest domestic popular hit ever, also called Loft (2008). In the period of 2013-2016, three more Dutch film remakes followed. In sum, 11 Dutch-Flemish film remakes (a total of 22 films) were released in the period 2000-2018, occasionally spurring other intra-European and even American remakes. Acknowledging that these remakes are temporally immediate (on average, they are released only 2.8 years after the source films) and monolingual (both the source movies and their remakes are in Dutch), this phenomenon appears to be highly peculiar within the European and even the global film (remake) industry.

In this article, we inquire into the process of film remaking generally, and into the practice of remaking films in two small to medium-sized European film regions specifically. More precisely, we examine which textual and contextual mechanisms are at the fundament of the practice. By textually comparing Dutch-Flemish remakes in tandem with their source films, a theoretical prism is conceived that helps us understand the workings and rationales behind (the making of) the film remake, and the contexts in which these are realized. We will demonstrate this by applying the prism to the context of Flanders and the Netherlands, which not only helps to elucidate the socio-cultural differences and similarities that may exist between these particular cultural contexts, but also how these variations can affect many types of differences between the Dutch and Flemish film versions.

1 Flanders is the Northern, Dutch-speaking part of Belgium. 


\section{The film remake as a prism}

As many scholars (e. g., Forrest and Koos, 2012; Mazdon, 2000; Verevis, 2006) have demonstrated, the film remake can be used to answer, or equally raise, all sorts of essential (audience-related, industrial, socio-political, textual, etc.) queries that surround, and in a sense also challenge, cinema. Therefore, one can approach the film remake as a kind of prism, a lens capable of refracting light rays, through which one can analyze the complex nature of the film medium on both the textual and contextual levels. Diverging from the still prevailing critical dédain towards the remake practice in popular discourses and adopting a non-normative standpoint, a plethora of possibilities is laid bare to acknowledge the film remake as both product and 'agent' of cultural practices and forces. Although any relation between film and culture is "complex, mediated and decentered" (Staiger, 2004, p. 128), one can argue that the (analysis of the) film remake reveals something about the cultural context in which the film is produced.

We argue that the use of the film remake as a prism holds the potential to 'defamiliarize' the familiar, the banal, or the elements that often go unnoticed when watching or analyzing film. As Thompson (1998, p. 11) makes clear, cinema can bear a 'defamiliarizing force', namely the capacity to exhibit familiar things, the everyday world and ideology in a deviating, unfamiliar or remarkable way, thereby providing opportunities for deeper insight. We claim that the use of the film remake as a prism holds an even bigger potential to 'defamiliarize'. Horton and McDougal (1998) already hinted at the analogy between this defamiliarizing force and the film remake by stating that remakes "provoke a double pleasure in that they offer what we have known previously, but with novel or at least different interpretations, representations, twists, developments, resolutions" (p. 6). This assertion, however, assumes that the audience has seen (or is at least is aware of) both (or more) versions of the film. However, this does not apply to, for example, the case of Dutch-Flemish film remakes (Cuelenaere, Joye, and Willems, 2016, p. 5). Having said that, we claim that the film remake is particularly well-suited for scholarly analysis as it is able to disentangle, locate or 'defamiliarize' the familiar, the banal, the unattainable and often invisible and render it more visible. The central element that makes this possible is the remake's inherent potential to be compared it with its predecessor(s), which helps to illuminate the (at first sight) banal interventions that were made to (re)create these films. As source films and remakes often have a more or less identical narrative and dialogic structure, the underlying, latent and ideologically informed meanings become more tangible when juxtaposing their different cinematic manifestations. By comparing a film remake with its source text(s) and looking into the re-contextualization of a spe- 
cific narrative, it becomes possible to acquire insights into the actual process of meaning-making in and by films.

Livingstone (2003, pp. 491-492) rightly asserts that "comparative research is challenging because one must balance and interpret similarities and differences while avoiding banalities and stereotypes" and points to an important conflict "between the apparent impossibility and the urgent necessity of comparison". As we will show, our findings underwrite the claim that the nature of the remake helps a lot in this process of comparison, but it is of absolute importance to embed our results in their specific socio-cultural context, not least to avoid the pitfall of reaffirming stereotypes. Therefore, in the following, we will briefly contextualize the Dutch-Flemish remake phenomenon.

\section{The monolingual Dutch-Flemish remake and its (production) context}

The neighbouring regions of the Netherlands and Flanders, also referred to as the Low Countries, share the same language and partly have a shared history. Moreover, the Dutch and Flemish film markets are quite similar, both being relatively small (Willems, 2017, p. 92). Nevertheless, both regions have many difficulties in finding an audience for each other's films. Apart from economic explanations (e. g., the lack of proper distribution networks and promotional opportunities), this indifference towards each other's films is symptomatic for a wider cultural shift. ${ }^{2}$ From the 1990 s on, the interregional contact and cultural exchange between Flanders and the Netherlands severely declined, so that fewer cultural products, including literature, radio, newspapers, television, and cinema (Cajot, 2012, p. 53)were shared. Rather than distributing each other's popular films, both regions opted for a commercially more interesting way to disseminate their stories beyond the domestic market, that is, by remaking them. This nuances the seeming 'indifference' between the Flemish and Dutch film markets: While audiences are not interested in films from the other region, filmmakers, in their search for stories to adapt, show a particular interest in these films. ${ }^{3}$

2 For a more in-depth analysis of this "cinematic indifference" in the Low Countries, see Cuelenaere, Willems, \& Joye, 2019, pp. 3-5.

3 This article focuses on mainstream popular films. In terms of successful releases across the Dutch-Flemish border, there is an interesting contrast between arthouse films, on the one hand, and mainstream films, on the other. In the broader context of Europe, mainstream films that perform well on the national level often experience several issues when released outside their 
Meir (2018) argues that "one of the most important recent developments in European cinema has been the formation of several companies that distribute films in some European and international territories simultaneously and who are capable of using this business model to finance internationally oriented films" (p. 1). Drawing from the exemplary case of the pan-European studio Studio Canal, he adds that "[r]emakes and readaptations are at the heart of its creative strategies" (Meir, 2018, p. 4). Although these film remakes are in need of localization strategies and thus tap into cultural specificity (to cross geographical, cultural and linguistic boundaries within a specific European context), they simultaneously seem to draw from well-known and established Hollywood industrial practices and creative tropes. This finding takes us back to the concept of "glocalization" (e.g., Robertson, 1995), which, in short, points towards the practice wherein global corporations localize their products to meet the preferences and tastes of local cultures. Even though this theory might be illuminating for the broader local-language remake phenomenon ${ }^{4}$, we claim that the Dutch-Flemish (or intra-European) remake phenomenon is of a different nature, albeit the same goal is shared: to attract local audiences. The difference lies in the fact that the film remakes in the Low Countries are not produced by large transnational corporations, but by small local production companies.

In this respect, the Dutch-Flemish phenomenon can be linked to another concept, called "delocalization", which is defined as a form of globalization (Straubhaar, 2007, p. 169) - there are other terms that denote the same idea, think of "internationalization" and "interlocalization" (Pym, 2017, pp. 123-124). This notion indicates the same phenomenon whereby, for instance, filmmakers produce movies both for their own and for other non-domestic markets. The

national borders (Higson, 2015, p. 138). European art films, however, at least in comparison to mainstream films, generally perform 'better' (taking into account the more modest box office expectations) (Jones, 2019). This partly explains the relative 'popularity' of the recent Flemish art films (think of films by directors such as Michaël Roskam, Fien Troch, Patrice Toye, and Felix Van Groeningen), which perform pretty well in the arthouse circuit in the Netherlands. For instance, the prominent art-house theater Louis Hartlooper Complex in Utrecht started a yearly film festival in 2013, devoted to Flemish (art-house) cinema. In 2015, it was retitled 'Belgian Film Festival'. The Netherlands are currently less internationally recognized for their arthouse films, which clarifies why there is no similar trend of watching Dutch art films in the Flemish arthouse circuit. 4 Think of companies like Globalgate Entertainment and Sony Pictures International Productions, which are divisions of the large transnational companies Lions Gate Entertainment Corporation and Sony Pictures Entertainment, respectively. They are made up of (or work closely together with) several locally oriented subdivisions (or national/local production companies) that localize/remake specific films, which are therefore called local-language remakes (see Labayen \& Morán in this special issue). 
crucial element of this idea is that filmmakers, before or while producing a film, not only prepare for the dissemination of that film in their own market, but also anticipate the foreign export - and in some cases only aim for the latter. This (double) anticipation often implies that local models are avoided in order to make them exportable (Straubhaar, 2007, p. 169). The problem with this concept is that it places too much emphasis on the aspect of anticipation of exportability during the process of film production. Although there are indeed many universal elements to be found in the Dutch-Flemish source films, almost all of them were exclusively produced for a domestic audience. This is also reflected in the marketing and distribution strategies for the films. Moreover, if these films were deliberately stripped of most of their local elements, a remake would make little sense, as it would probably be less complicated to successfully release them elsewhere. Considering these issues, we might call this ambiguous phenomenon 'manufacturing (cultural) proximity' (see also Labayen and Morán in this special issue), as it takes into account both processes: cultural proximity, by which Straubhaar (2007) means that audiences usually prefer cultural products that are as close as possible to their local "language, ethnic appearance, dress, style, humor, historical reference, and shared topical knowledge” (p. 26), and the more commercially driven strategies, such as remaking and relying on, for instance, genre logic.

Building on this notion, and linking it to our concept of 'the remake as a prism', this article emphasizes the often conscious and active decisions made by filmmakers who want to make their filmic creations (in this case remakes) recognizable or familiar, and, therefore, balance between local and global cultural aspects. However, as we will claim, the study of film remakes should deal with issues of localization, but equally with more formal and (trans)textual matters, which are, for example, often related to filmmakers' personal preferences and motivations.

\section{Method}

At the time of our analysis, a total of 18 films had been released, consisting of five Flemish remakes and their Dutch source films and four Flemish source films in tandem with their Dutch remakes (Table 1). We created a model that operationalizes the concept of the remake as a prism by systematically comparing the nine film remakes with their nine source films. By looking at the different textual similarities and differences, the model helps to pinpoint specific textual mechanisms that are inherent to the remake practice. The model is inspired by Moran's format adaptation model (2009) and Genette's categorization of textual transcendence 
(1997a, 1997b). First, a detailed sequence analysis of every single film was made, meaning that each film was divided into meaningful segments, which can then be clearly defined for analytical purposes (Van Kempen, 1995, p. 131). Subsequently, drawing on Moran's model for the analysis of television formats, we traced elements that are part of three different codes, that is, the formal, transtextual and cultural. The formal code consists of, inter alia, the mise-en-scène, cinematography, sound, editing, narrative, characters, etc. The transtextual code is inspired by Genette's notion (and subsequent categorization) of transtextuality, which signifies "all that sets the text in a relationship, whether obvious or concealed, with other texts" (Genette, 1997a, p. 1). Lastly, the cultural code encompasses all explicit and implicit cultural references, including references to sexuality, humor, gender, ethnicity, and others as well as broader political, judicial, economic or geographic circumstances. In the last step, a separate analysis is conducted for each tandem (a source film together with its remake), in which all sequences of both films are systematically compared while taking into account the three codes. This is, of course, a multi-layered process, as the three codes overlap, interact, and connect. By comparing a source text with its remake along these three codes, a prism is conceived that helps us to locate or structure the elements that impact or create the meaning(s) of a text (in relation to other texts).

Table 1: List of films analyzed, together with the English title or our own translation of the original title, year of release, director, country of production.

\begin{tabular}{ll}
\hline Source film & Film remake \\
\hline All Stars (1997, van de Velde, NL) & Team Spirit (2000, Verheyen, BE) \\
In Orange (In Oranje, 2004, Lürsen, NL) & Gilles (Buitenspel, 2005, Verheyen, BE) \\
Love Is All (Alles is Liefde, 2007, Lürsen, NL) & $\begin{array}{l}\text { Crazy About Ya (Zot van A., 2010, Verheyen, BE) } \\
\text { Loft (2008, Van Looy, BE) }\end{array}$ \\
Madly in Love (Smoorverliefd, 2010, Van & Madly in Love (Smoorverliefd, 2013, Van \\
Mieghem, BE) & Mieghem, NL) \\
Come as You Are (Hasta La Vista, 2011, & Goodbye, My Friends (Adios Amigos, 2016, van \\
Enthoven, BE) & Rees, NL) \\
Brasserie Romantique (Brasserie Romantiek, & Brasserie Valentine (Brasserie Valentijn, 2016, \\
2012, Vanhoebrouck, BE) & Vogel, NL) \\
Family Way (Alles is Familie, 2012, Lürsen, NL) & The Family Way (Allemaal Familie, 2017, Vos, BE) \\
Men's Hearts (Mannenharten, 2013, de Cloe,, & What Men Want (Wat Mannen Willen, 2015, \\
NL) & Peeters, BE) \\
\hline
\end{tabular}

5 Men's Hearts is itself already a remake of a German film called Männerherzen (2009, Verhoeven). 


\section{Results}

\section{Formal code}

Overall, our results show that filmmakers try to keep a balance between a more or less universal framework (i. e., dialogic structures, themes, narratives, spaces, characters, even production tactics) and a local interpretation or 'reality'. This is, for example, reflected in how spaces remain the same, but (geographical) locations almost always change. While the Dutch Love is All is set in the modern city of Amsterdam, the Flemish remake is set in a similar trendy city, Antwerp. It is also interesting that both films clearly want their audiences to know that the narratives take place in these respective cities. Indeed, it looks as if the Flemish remake copied the (overt) city marketing strategy of the Dutch source film. This points to the fact that film remakes not only reuse narratives and other formal or stylistic decisions but also appropriate production strategies. Another example of this mix between universalism and localism relates to the characters who were employed in the narratives of source films and remakes: Many of the remakes (more or less) kept the same personalities and characteristics of the source story's characters, but the actors were changed to (sometimes very similar-looking) popular local-language actors.

Notwithstanding the uniqueness and complexity of each film tandem, on a general level all of the films are stylistically quite conventional. One could argue that, in most cases, the cinematography and editing serve the continuity or clarity of the story: The shots are graphically, spatially and temporally continuous. The latter probably has to do with the fact that all movies were, in fact, high concept, mainstream genre films (cf. transtextual code), clearly inspired by Hollywood conventions. However, when looking at individual cases, we found a few compelling differences between films in tandem that may help us to understand the (textual) mechanisms of films, as well as the production and cultural context surrounding it.

Although there are a few exceptions, we discovered that - in comparison to the Flemish versions - many of the Dutch films were stylized more according to mainstream Hollywood aesthetics. Looking at the romantic comedies in our sample (10 films in total), most of the Dutch versions could be considered as 'cleaner' (i. e., more use of high key lighting and vivid colors), while the Flemish films were darker, using less expressive lights and colors. This may have to do with higher production values in Dutch cinema as well as with the general Dutch film production culture (also policy-wise) that seems to be more focused on mainstream films. Another argument that confirms the thesis of higher production 
values in the Dutch cinema is that generally speaking, more Anglophone popular music is used in the Dutch versions, while the Flemish films make more use of less expensive - popular Flemish songs.

For both Flemish and Dutch remakes, there were quite a few instances where small formal (often visual) changes had a significant impact on how narratives are conceived and, consequently, might influence how audiences interpret these narratives. An example of this was found in Loft: In both versions of this whodunit, there is a crucial scene in which the villain meets his victim for the first time. In the source film, the character who first looks at the victim is not the villain. In the Dutch version, however, the character who first stares at the victim is the villain of the story. This is made explicit cinematographically by placing the villain's face in the center of the frame and putting him in medium close-up, therefore making his actions more noticeable. By changing this small formal detail, the filmmakers of the Dutch remake might have indirectly made it easier for the audience to trace the 'bad guy'.

Related to the latter is a mechanism that we uncovered in our analysis of formal codes, which could be dubbed 'filling in the gaps'. This concept points towards the rendering explicit, obvious or clear previously ambiguous or implicit narrative elements or meanings in the source film. Known as a concept in the field of adaptation studies, filling in gaps is generally defined as an active process by audiences of completing, or rather interpreting, specific lacunas that are inherent to all texts (Iser, 1972, pp. 284-285). Our results, however, show another - but related - mechanism, wherein gaps (or blanks) in the source film are filled in by the filmmakers themselves in the remake they produce. We found many types of gaps in our analysis, ranging from ambiguous, illogical or unexplained narrative elements to little narrative or visual 'mistakes' and other unfinished elements in the source films. When looking for those gaps in the remakes, we found that many of them were 'solved', which might point to a compulsion among these mainstream filmmakers to optimize or improve an existing story or the visual representation of that story. Clear examples of this can be found in the Dutch remake Madly in Love $e^{6}$ When Bob, a male side character, calls Judith "elysian”, the word is explained on-screen via paratextual markers, whereas the Flemish source film does not provide the audience with an explanation. Somewhat later in the Dutch remake, there is a scene that shows (and explains) how Judith gets the central role in a play. In the Flemish source film, however, there is no such explanation

6 Madly in love is actually an auto-remake, which means that the director in charge of the remake is the same as for the source film. Even though this might naturally facilitate the 'solving' of gaps (since the director gets a second take), we found ample instances of very similar processes in non-auto-remakes. This proves that this process is not confined to auto-remakes only. 
as we suddenly see her play the lead of a play. This latter gap, however, is not only rendered explicit in the remake through visual elements, but equally through the dialogue of these characters and more narrative aspects of the film.

We also found instances where seemingly unimportant ambiguous, unexplained or implicit narrative elements in the source film were made explicit in the film remake, which led to big narrative changes or adjustments. One illuminating example can be found at the end of the Flemish source film Brasserie Romantique. It is shown how the female lead, the owner of a restaurant, finds it weird that during that evening there was one reserved table in the restaurant that was left untouched because the people did not show up. Eventually, at the end of the movie, there is no explanation whatsoever as to why this might have been of importance to the narrative. In the Dutch remake (Brasserie Valentine), however, the same happens, but right after this particular scene, the restaurant owner receives a call from a couple who say they are sorry because they could not make it that evening. In fact, the two people who call her are two new characters who were added to the plot, and whom we followed throughout the whole film. This added plot line did not only fill in a gap (of the empty table) of the source film, but simultaneously gave the film a more positive ending, as these two characters fell in love. This type of gap might indicate how filmmakers of mainstream films want to streamline, clarify, and in some instances simplify their films, ultimately in order to make them more digestible and to reach larger audiences.

The abovementioned types of gaps could be called "intertextual gaps", as these are "exposed, constituted, and displayed [...] by both translations and adaptations” (Leitch, 2017, p. 58). Comparing Dutch-Flemish film tandems allows us to observe filmmakers filling gaps within source films, thus rendering this process quite explicit. Therefore, in our case, and in comparison to intertextual gaps generally discussed by adaptation scholars, it could be argued that the filmmakers of the remake indirectly create the gaps of the source film - by filling them in the remake. ${ }^{7}$ As Flemish and Dutch audiences seem unaware of each other's films, and consequently do not know that the remake they watch is, in fact, a remake, these gaps are not constituted (and filled) in their minds, but in the minds (and films) of the filmmakers and the scholars that analyze these texts. Hence, these gaps only exist in the intertextual relationship between a source film and its remake, which brings us to another type of code, including the intertextual ties between film tandems.

7 We do not intend to suggest that the source film is deliberately kept vague so that there is an extra reason to produce a remake, that is, as an improved version. Rather, we argue that when filmmakers of a remake decide to fill in what they consider to be a gap in the source film, this may not have been perceived as such by the filmmaker of the source text. 


\section{Transtextual code}

Genette's idea of transtextuality covers those textual elements that link (directly and indirectly) a film text to other (film) texts. Transtexuality not only comprises the relationships between source films and remakes but, also, for instance, a film text and similar films of the same genre (cf. architextuality). Moreover, it encompasses those elements that accompany or surround the main text (think of titles, intertitles, credits, etc.), called paratexts. By analyzing the paratextual aspects of our Dutch-Flemish films, we found that filmmakers avoid using the term remake when referencing the source text in the film credits. In contrast, they preferred terms like adaptation, inspiration, even format, and in one case, the production team of the Dutch remake of Madly in Love did not mention anything that hinted at it being an adaptation or remake. This finding is also reflected in the marketing of the films where the (textual) status of these films (being remakes) is never mentioned. This might indicate the pejorative connotation of the film remake, which, in turn, illustrates a broader negative discourse surrounding the phenomenon, and as a result, the unwillingness of filmmakers to label their works as film remakes. Such observations are in line with the recent shift in communication strategies of most Hollywood studios, which avoid "the negative aura of the remake practice by promoting the films using different language" (Cuelenaere, Joye, and Willems, 2016, p. 5). At the same time, the rationale behind these strategies is also of a distinct nature because the Dutch-Flemish audiences who watch these film remakes are what Linda Hutcheon would call "unknowing audiences": people who are unaware that these films are in fact adaptations (in this case remakes), perceiving them as "original" films. Even though Flanders and the Netherlands might be considered culturally, geographically, and linguistically proximate, they do not seem to be aware of each other's films. ${ }^{8}$ As a result, these Dutch-Flemish film remakes "have a way of upending sacrosanct elements like priority and originality" (Hutcheon, 2012, p. 122). Moreover, it seems that Hutcheon's (2012, p. 121) statement that "[f] or an adaptation to be successful in its own right, it must be so for both knowing and unknowing audiences" does not apply to the successful Dutch-Flemish remake phenomenon. Except for some film buffs, critics, and scholars, there is hardly a knowing audience, and if people do know that the Dutch-Flemish film remake they are watching is actually a remake, most of them will not have seen the source text and are therefore unable to compare

8 Which, by extension, also helps to explain why distributors decide not to mention the existence of the source films in the marketing of these remakes, - the Dutch and Flemish audiences are generally unaware of each other's films. 
both versions. Consequently, and according to Druxman's (1975) typology, the Dutch-Flemish remakes could be labeled as "disguised remakes", a term which denotes those film remakes that do not draw attention to their source text(s), or the "unacknowledged disguised remake", whereby the audience "is deliberately uninformed about the switches” (Greenberg, 1998, p. 126), and, in our case, about its status as a remake.

Connected to the latter, it is remarkable to see that - although the Dutch-Flemish filmmakers of remakes seem to be well aware that the current public opinion towards the film remake is rather negative - some of them incorporate (often ironically) intratextual references to the process of remaking in their film remakes, or to the source films on which their remake is based. Such playful references can be found in rather small details, as, for instance, a pub in Team Spirit is named after the title of its Dutch source film, All Stars. Another example of such a small detail is that the real name of one of the actors in All Stars became the equivalent character's name in the Flemish remake. There are, however, also more apparent illustrations of this practice. In the Flemish remake The Family Way, the profession of one of the male main characters was changed from that of song producer to film director. More specifically, this director not only wanted to make a sequel of one of his own films, but also an American remake. This narrative element in The Family Way is thus both an intratextual reference to its own textual status (being a remake) and a metatextual reference, which "unites a given text to another, of which it speaks without necessarily citing it" (Genette, 1997a, p. 4). This 'speaking of' is, in the case of our sample, often in the form of critique of another film or film genre. Indeed, the previously mentioned film director in The Family Way suddenly makes a joke to his cameraman when talking about a loft in America: "This would, by the way, be the first successful loft in America." What he is referring to is the unsuccessful release of the American remake of the Flemish film Loft, which was quite a big media event in Flanders in 2014 (see also Cuelenaere, Willems, and Joye, 2018). Hence, even though all of the Dutch-Flemish remakes avoid the use of the remake label, many of them do not flinch from introducing a playful self-reflexive attitude towards the remake phenomenon.

The most abstract category of transtextual ties is called architextuality, pointing to "the relationship of inclusion linking each text to the various kinds of discourse of which it is a representative" (Genette, 1997b, p. 19). Genre is one of the important aspects of this category. Analyzing these films, it quickly became clear that all of the 18 films were genre films, with 10 out of 18 being romantic comedies. The latter confirms the hypothesis that Hollywood's focus on high-budget blockbuster films opened up a gap for mid-budget, local-language genre films like rom-coms (Roxborough and Brzeski, 2018). This is in line with European studios like Studio Canal, who heavily rely on generic (Hollywood) models and 
favor "a number of genres, particularly those of the romantic comedy, the action film and family films" (Meir, 2018, p. 4). This hints at an ambiguous imbrication of the Dutch-Flemish filmmakers and the mainstream Anglo-Saxon film industry, which is characterized by both differences and clear overlap. Concerning the latter, we found apparent resemblances between, among others, the popular romantic comedy Love Actually (Curtis, 2003) and most of the Dutch-Flemish rom-coms that were remade. Not only on the level of narrative, themes, and style, but also in terms of promotional material and other marketing tools, there are many similarities to be found. Interestingly enough, according to the quantitative research of Follows (2015), the percentage of Hollywood remakes that are romantic comedies is only $3 \%$, while the broader genre of comedy amounts to $7 \%$. When comparing the latter percentages with, for example, the horror genre (29\%) or the musical genre $(27 \%)$, there appears to be a huge difference to the Dutch-Flemish remake phenomenon 9 . Moreover, according to Mazdon (2000), when looking more closely at Hollywood remakes of (romantic) comedies, "plots and many of their jokes and gags undergo little change during the remake process" (p. 92). In this context, our analysis again points to the thesis of a universal structure with a local interpretation: It confirms the claim that plots generally undergo little adjustments, but it contradicts the idea that jokes and gags are often not altered in the remake as we found many instances of small and big changes. One example of the former is when in the Dutch version of Madly in Love one of the jokes of the source text is slightly adjusted. Whereas the main character of the Flemish film, Judith, all of a sudden says: “[...] he was also a sex animal, and as far as I know, he was the first guy who took out his dentures while eating pussy", the Dutch equivalent of the same character says: "He was a sex animal! He was the only man who, while eating pussy...”, but does not finish her sentence as someone else stops her from saying out loud what she thinks. The director herself mentioned in an interview that she changed this joke for two reasons: first, because the actors on stage found it too dirty, and secondly, because of the Dutch context, as, according to her, dentures do not exist anymore in the Netherlands (Vermeersch, 2013, p. 57). An example of a bigger change to humor can be found in Family Way: The scene wherein the parents of the main characters tell their children that they want a divorce is quite serious. The aim is clearly to ensure that the spectators take this seriously and empathize with the main characters. In the Flemish remake, however, this moment is presented humorously: When, during

9 Ten out of eighteen films from our sample are romantic comedies, four are tragicomedies, two are family films, and two are thrillers. These are the main genres of the films but many of them could be categorized into several subgenres. 
a game of Pictionary, the father wants to tell his children about the divorce, they force him to draw his message on a big board. At first, he refuses to do so, but after being put under pressure, he eventually tries to draw the whole situation. The children start to guess, and eventually when Steve guesses the right answer, he happily shouts: "Yes!” The others now know what is going on (their parents are getting a divorce), but Steve does not, which makes the whole situation tragically funny. Our results thus endorse the idea that humor is an element that impedes border crossing (Lee, 2008; Palmer, 1995), which, indirectly, means that the Low Countries do not always share the same humor. The latter element, which is often related to differences in culture, brings us to the last code.

\section{Cultural code}

As mentioned, the cultural codes of a film indicate implicit and explicit references to specific cultural elements or contexts. Therefore, these codes often denote what we previously called a process of localization, that is, adjusting filmic aspects to a particular socio-cultural context, often with the aim of recreating a recognizable reality and national identity. As Billig (1995) claims, nationalism is not to be reduced to the palpable or visible (e.g., propagandist) appearances or articulations of nationalism. Likewise, Billig (1995) coined the concept "banal nationalism" which refers to the "ideological habits which enable the established nations of the West to be reproduced” (p. 6). Applying Billig's concept to film, Hjort (2000) coined another term, "banal aboutness", pointing towards banal reproductions of national identities in a film while not being explicitly national regarding its central themes. The concept is grounded in features such as language and mise-en-scène, which are often overlooked by both domestic and international audiences. Our analysis, however, shows that the prism of the remake helps us to trace such banal reproductions of national identities. By looking at the changes made to the cultural codes in film remakes, mechanisms are laid bare that may help explain how filmmakers localize their cultural products. According to Hall (1997, p. 15), cultural (and national) identities are constructed within specific representations, broader discourses, and concrete practices. Moreover, these identities have less to do with who we are or where we were born, and more to do with how one is presented and how that might influence how we present ourselves (Hall, 1996, p. 4). The abovementioned mechanisms were shared in all of the films we analyzed, which shows that there are patterns to be found in how national identities are represented and recreated in these popular films. As Dhoest (2004, p. 35) argued in the context of popular national television, fiction is an excellent way to penetrate the collective consciousness, and therefore, there 
is, at the very least, a minimal connection between fiction and cultural identity. Moreover, he adds that the specific content also plays a significant role, that is, as a source of explicit or implicit cultural representations.

There is a plethora of representational themes that are structurally changed in almost all of our films: sexuality, nudity, ethnicity, religion, sports, and specific cultural habits and traditions. These aspects were, as we will explain, mostly referenced implicitly, while the more explicit references were mostly concerned with, among others, television programs, magazines or newspapers, theme parks, or even local actors and celebrities. An example of such explicit references is found in Family Way when Charlie takes the teenage son of one of his friends to the Efteling, a famous Dutch theme park. Moreover, when visiting the park, there is a cameo by Gers Pardoel, a famous Dutch singer, who is seen selling waffles. In the Flemish remake, the plot did not change, but the theme park and cameo did: They visited Plopsaland instead and met Gert Verhulst, a famous Flemish entertainment figure, who in this case played himself, being the CEO of the entertainment company Studio 100, which owns the theme park. As said, there were a lot of adjustments on the level of implicit cultural references as well. The most striking and obvious one is the representation of sexuality and nudity. For almost all of our cases, the Dutch versions were (a lot) more explicit in terms of (mostly female) nudity and sexual contact or conversations. We claim that these banal adjustments are made due to the filmmakers wanting to shape their films according to their specific realities, which is in line with the concept of banal aboutness. The Dutch culture is indeed known for its permissiveness and general tolerance, not only towards sexuality but also gender, ethnicity, etc. Although many academics nuance this so-called Dutch tolerance (see i.a., Buruma, 2006; Verstraten, 2018), almost all of the Dutch filmmakers in our sample seem to have employed the idea that the Dutch film industry, and more broadly its society, is known for its tolerance, which ultimately resulted in more nudity.

Ethnicity, or multiculturalism, in combination with religion, is also aspects that were structurally altered in the selected remakes. Although there are some counter-examples; the Dutch versions included more non-white actors than the Flemish versions. This occurred in both directions, by changing white actors in the Flemish version to non-white actors in the Dutch versions, or by changing non-white characters in the Dutch source film to white ones in the Flemish remake. For instance, in the Dutch remake of Loft, several characters that were originally played by white actors were changed into non-white actors. More specifically, the villain par excellence, played by the white actor Matthias Schoenaerts in the Flemish Loft, is, in the Dutch version, played by Marwan Chico Kenzari, a non-white actor of Tunisian descent. Van Looy, the director of the Flemish source film, asserted that he did not dare to let that specific character be played by a 
non-white actor as he was afraid of being criticized (Cuelenaere, Willems, and Joye, 2018, pp. 273-274). Again, this can be linked to the Dutch ideal of being a highly tolerant society, which would be, at least according to Van Looy, different in Flanders (for more information, cf. Cuelenaere, Willems, and Joye, 2018). It is also notable to see that, in some cases, together with ethnicity, the religious background of specific characters changed in the remake process. While in the Dutch source film In Orange there is a family of Surinamese descent, this is altered to a Congolese family in the Flemish Gilles. Indeed, even colonial histories are remade in these films. Moreover, the 'corresponding' religions and related rites are remade as well: Whereas the grandmother of the Surinamese family practices "Winti" (a traditional Afro-Surinamese religion) to talk with the dead in the Dutch version, the Flemish equivalent of the grandmother practices something called "Orun-rere". This is the concept of the hereafter in the Yoruba religion (Balogun, 2013, p. 113). However, the Yoruba people are geographically situated in Nigeria, Benin, and to a lesser extent in Ghana, Togo, and Ivory Coast - not in Congo. It is unclear why the Flemish filmmakers made this obvious 'mistake', as the most prominent religion in Congo is Christianity, which has its own idea of the afterlife. Most probably, this is because in Christianity, there is no real way of communicating with the dead, which is why the filmmakers searched for a random African religion that does include this means of contact. This confirms the notion of banal aboutness, but at the same time reveals an essentialist conception of Africa as a homogenous entity, resulting in an incorrect and stereotyped depiction of Congo. It, therefore, seems to be of less importance that this recreated banal reality is actually embedded in an existing reality. Hence, how a (filmic) world is (re)created is of secondary concern, as long as it is recognizable to the target audience. However banal some of the aforementioned adjustments might appear at first sight, they actually indicate the importance of evoking a specific national identity. All of these films are basically universal genre films, but they are still in need of localized elements that induce an identifiable realism.

\section{Conclusion and discussion}

The primary objective of this article was to inquire into the process of film remaking, which, in the past decades, has shown itself to be of great importance in the film industries of the Low Countries, and of Europe by extension. By conducting a comparative film analysis of nine Dutch-Flemish remakes in tandem with their nine source films, we discovered which textual and contextual mechanisms are at the basis of this phenomenon. After arguing that the film remake can be con- 
sidered as a prism that helps to deconstruct myriad elements that are related to cinema, and to embed the practice in its socio-cultural and industrial context, we showed which similarities and differences were found between the Dutch and Flemish film versions and how these can be interpreted.

Our results were structured along three different codes that are central to our model of comparison, that is, the formal, transtextual, and cultural codes. Although these codes intersect and overlap, they help a lot in discovering the different mechanisms that are at play in the remake process. On a more abstract level, we distilled two overarching principles that govern the Dutch-Flemish remake practice. The first important element that defines a great deal of the remake process points towards the concept of localization. Many of the changes made to the formal, transtextual, and cultural codes of our films suggest differences in (film) culture between the Netherlands and Flanders. However, instead of claiming that these differences indicate clear-cut cultural differences, we argue that they are rather symptomatic of the processes of 'manufacturing proximity' and 'banal aboutness'. Both suggest that these localized elements are the result of the perceptions of cultural differences and stereotypes held by filmmakers. Indeed, these films do not "simply represent or express the stable features of a national culture, but are themselves one of the loci of debates about a nation's governing principles, goals, heritage and history" (Hjort and MacKenzie, 2000, pp. 3-4). When, for instance, employing the ideal of Dutch tolerance, or connecting a random religion to a country, these filmmakers want to recreate a world that is banally connected to the reality of their audience. This 'aboutness' is therefore not only ideologically informed, but also (if not mainly) commercially driven. Besides such local interpretations of filmic elements, we also found several (quasi)universal aspects included in these films. Such universalities were located in similar dialogic structures, spaces, characters, themes, or even production tactics. Hence, the films put under analysis showed a mix of both universalism and localism.

The second important encompassing finding was that there are also quite a lot of elements that are not related to the strategy of localization. While much of the literature in the field of remake studies focuses on the issues of localization and cross-cultural adaptation, other, equally important textual and contextual elements might be neglected. This article, therefore, wishes to start a trend wherein a more holistic approach to the film remake is adopted. One feature that we, for instance, discovered is what might be called the mechanism of 'filling in the gaps', whereby filmmakers render elements that were unclear, ambiguous or (too) complex in the source film more explicit, unambiguous or simplified in the remake they produce. These changes may point to many different rationales, ranging from financial incentives and personal opinions to filmic 'corrections'. 
We also found that filmmakers in Europe might also be aware of the negative connotation of the film remake, which is why they avoid the use of the label "film remake" in the credits (and promotion) of their films. However, these same filmmakers did not shy away from employing a self-reflexive attitude towards the remake phenomenon in their films. When looking beyond the processes of localization, researching film remakes can tell us a lot about how film texts are constructed and how these are able to create and transform meanings.

This article demonstrated the analytical value of the prism of the film remake by focusing on the significant textual similarities and differences between two versions of one (almost indistinguishable) narrative. By addressing the complicated embedment of the Dutch-Flemish remake phenomenon in a European context, while pointing towards the hyper-relevant links but also differences to Hollywood practices, this argument was also extended to the contextual level. The prismatic film remake helped us reveal and better understand not only contextual but also formal and (trans)textual mechanisms that are part of the filmic and cinematic medium.

\section{References}

Balogun, B. J. (2013). The consequentialist foundations of traditional Yoruba ethics: An exposition. Thought and Practice, 5(2), 103-121.

Billig, M. (1995). Banal nationalism. Thousand Oaks: Sage.

Buruma, I. (2006). Murder in Amsterdam: The death of Theo Van Gogh and the limits of tolerance. New York: Penguin.

Cajot, J. (2012). Waarom het Verkavelingsvlaams onvermijdelijk was [Why the Flemish intermediate language was unavoidable]. In K. Absillis, J. Jaspers, \& S. Van Hoof (Eds.), De manke usurpator: over Verkavelingsvlaams (pp. 39-66). Ghent: Academia Press.

Cuelenaere, E., Joye, S., \& Willems, G. (2016). Reframing the remake: Dutch-Flemish monolingual remakes and their theoretical and conceptual implications. Frames Cinema Journal, 10.

Cuelenaere, E., Willems, G., \& Joye, S. (2018). Same same same, but different: A comparative film analysis of the Belgian, Dutch and American Loft. Tijdschrift voor Communicatiewetenschap, 46(4), 263-279.

Cuelenaere, E., Willems, G., \& Joye, S. (2019). Remaking identities and stereotypes: How film remakes transform and reinforce nationality, disability, and gender. European Journal of Cultural Studies. doi:https://doi.org/10.1177/1367549418821850

Dhoest, A. (2004). De verbeelde gemeenschap [The imagined community]. Leuven: Leuven University Press.

Druxman, M. B. (1975). Make it again, Sam. Cranbury: A. S. Barnes.

Follows, S. (2015, June). The scale of Hollywood remakes and reboots. Stephen Follows Blog. Retrieved August 12, 2018 from https://stephenfollows.com/hollywood-remakes-andreboots/. 
Forrest, J., \& Koos, L. R. (Eds.) (2012). Dead ringers: The remake in theory and practice. New York: SUNY Press.

Genette, G. (1997a). Palimpsests: Literature in the second degree. Lincoln: University of Nebraska Press.

Genette, G. (1997b). Paratexts: Thresholds of interpretation. Cambridge: Cambridge University Press.

Greenberg, H. R. (1998). Raiders of the lost text: Remaking as contested homage in 'Always'. In A. Horton \& S. Y. McDougal (Eds.), Play it again, Sam (pp. 115-130). Berkeley: University of California Press.

Hall, S. (1996). Introduction: Who needs “identity"? In S. Hall \& P. du Gay (Eds.), Questions of cultural identity (pp. 1-17). London: Sage.

Hall, S. (1997). Representation: Cultural representation and signifying practices. London: Sage.

Higson, A. (2015). British cinema and the global reach for audiences. In I. Bondebjerg, E. N. Redvall \& A. Higson (Eds.), European cinema and television (pp. 127-150). Basingstoke: Palgrave Macmillan

Hjort, M. (2000). Themes of nation. In M. Hjort \& S. MacKenzie (Eds.), Cinema \& nation (pp. 103-117). London: Routledge.

Hjort, M., \& MacKenzie, S. (2000). Introduction. In M. Hjort \& S. MacKenzie (Eds.), Cinema \& nation (pp. 1-14). London: Routledge.

Horton, A., \& McDougal, S. Y. (Eds.) (1998). Play it again, Sam (pp. 115-130). Berkeley: University of California Press.

Hutcheon, L. (2012). A theory of adaptation. London: Routledge.

Iser, W. (1972). The reading process: A phenomenological approach. New literary history, 3(2), 279-299.

Jones, H. (2019, in press). What makes European films travel? In I. Lewis \& L. Canning (Eds.), European cinema in the $21^{\text {st }}$ century: Discourses, directions and genres. Basingstoke: Palgrave Macmillan.

Lee, F. L. (2008). Hollywood movies in East Asia: Examining cultural discount and performance predictability at the box office. Asian Journal of Communication, 18(2), 117-136.

Leitch, T. (2017). Mind the gaps. In J. Grossman \& B. R. Palmer (Eds.), Adaptation in visual culture (pp. 53-71). Cham: Palgrave Macmillan.

Livingstone, S. (2003). On the challenges of cross-national comparative media research. European Journal of Communication, 18(4), 477-500.

Mazdon, L. (2000). Encore Hollywood. London: British Film Institute.

Meir, C. (2018). European cinema in an era of studio-building: Some artistic and industrial tendencies in Studiocanal's output, 2006-present. Studies in European Cinema, 1-17. doi:10.1080/17411548.2018.1471030

Moran, A. (2009). When TV formats are translated. In A. Moran (Ed.), TV formats worldwide: Localizing global programs (pp. 41-54). Bristol: Intellect books.

Palmer, J. (1995). Taking humor seriously. London: Routledge.

Pym, A. (2017). Exploring translation theories. London: Routledge.

Robertson, R. (1995). Glocalization: Time-space and homogeneity-heterogeneity. Global modernities, 2, 25-45.

Roxborough, S., \& Brzeski, P. (2018, February). Why local-language remakes are thriving at the global box office. The Hollywood Reporter. Retrieved July 2, 2018 from https://www. hollywoodreporter.com/news/berlin-why-local-language-remakes-are-thriving-at-globalbox-office-1085701. 
Staiger, J. (2004). The future of the past. Cinema Journal, 44(1), 126-129.

Straubhaar, J. D. (2007). World television. Thousand Oaks: Sage.

Thompson, K. (1998). Breaking the glass armor. Princeton: Princeton University Press.

Van Kempen, J. (1995). Geschreven op het scherm [Written on screen]. Utrecht: LOKV.

Verevis, C. (2006). Film remakes. Edinburgh University Press.

Vermeersch, E. (2013). Remakes binnen eenzelfde taalgebied [Remakes within the same linguistic area]. Unpublished master's thesis, Ghent University, Ghent, Belgium.

Verstraten, P. (2018). The freedom to make racial jokes: Satires on nationalism and multicultural comedies in Dutch cinema. In H. James (Ed.), Nationalism in contemporary Western European cinema (pp. 125-143). Basingstoke: Palgrave Macmillan.

Willems, G. (2017). Subsidie, camera, actie! Filmbeleid in Vlaanderen (1964-2002) [Subsidy, camera, action! Film policy in Flanders (1964-2002)]. Ghent: Academia Press. 